\title{
Avaliação da Qualidade Microbiológica de Produtos Saneantes Destinados à Limpeza
}

\author{
Adriana Bugno*, Adriana Aparecida Buzzo, Tatiana Caldas Pereira \\ Instituto Adolfo Lutz, Seção de Controle de Esterilidade e Pirogênio, São Paulo
}

*Correspondência:

A. Bugno

Instituto Adolfo Lutz

Seção de Controle de Esterilidade e

Pirogênio

Av. Dr. Arnaldo, 355

01246-902 - São Paulo - SP

E-mail: adrbugno@ial.sp.gov.br
Detergentes e seus congêneres são produtos destinados à limpeza e higienização de objetos inanimados elou ambientes. As empresas que produzem ou importam os produtos mencionados devem cumprir as Boas Práticas de Fabricação e Controle, com a finalidade de garantir a qualidade e a segurança de uso destes produtos. Este estudo teve por objetivo avaliar a qualidade microbiológica de detergentes e seus congêneres. Cento e quatro amostras foram analisadas no periodo entre Abril de 2001 e Outubro de 2002, sendo que 41\% das amostras analisadas apresentaram crescimento microbiano.
Unitermos:

- Microrganismos

- Contaminantes

- Detergentes

\section{INTRODUÇÃO}

Produtos saneantes domissanitários classificados quanto à finalidade de uso, como produtos para limpeza geral e afins são definidos na Resolução RDC n ${ }^{\circ} 184$, de 22/10/01, da Agência Nacional de Vigilância Sanitária, como aqueles destinados à higienização de objetos inanimados e/ou ambientes domiciliares, coletivos e/ou públicos, tanto para fins domésticos quanto para fins profissionais (Brasil, 2001).

Esta Resolução, que define os procedimentos a serem adotados para o registro de produtos saneantes domissanitários, estabelece que "as empresas legalmente autorizadas a produzir ou importar estão sujeitas à verificação do cumprimento das Boas Práticas de Fabricação e Controle".

A ênfase às Boas Práticas de Fabricação e Controle (BPF e C) iniciou nos Estados Unidos da América, decorrente da ação regulatória do Food and Drug Administration (FDA). A abrangência nacional ou internacional destas normas está direcionada tanto às instituições da área da saúde, quanto à atividade industrial dos produtores de medicamentos, correlatos, cosméticos, domissanitários e alimentos.

Para as Indústrias de Saneantes Domissanitários, as diretrizes para a implantação das Boas Práticas de Fabricação e Controle (BPF e C) estão estabelecidas na Portaria $n^{\circ} 327$, de 30 de julho de 1997, da Secretaria Nacional de Vigilância Sanitária, do Ministério da Saúde, as quais visam à padronização e definição de procedimentos, métodos de fabricação, condições das instalações da empresa, equipamentos e respectivas manutenções, critérios de segurança, bem como matérias-primas, embalagens, condições de estocagem e aspectos relativos ao meio ambiente, como forma de garantir a qualidade e a segurança no uso destes produtos (Brasil, 1997).

O controle da contaminação microbiana é um aspecto importante das BPF e $\mathrm{C}$ e deve ser parte integrante de programas de Garantia da Qualidade (Sharpell, Manowitz, 1991). Inicialmente o controle microbiológico do processo era associado à fabricação de produtos estéreis, porém verificou-se que a contaminação microbiana pode acarretar problemas em ampla abrangência de produtos, comprome- 
tendo a qualidade final do produto ou a sua segurança de uso, intimamente ligadas ao risco de infecção (Sharpell, Manowitz, 1991; Pinto, Kaneko, Ohara, 2000).

A avaliação do risco de infecção associada a estes produtos deve ser realizada considerando-se vários fatores, entre os quais pode-se citar a finalidade de uso, as condições sob as quais o produto será utilizado, a população exposta, a freqüência e o tempo de exposição ao produto, bem como as características dos microrganismos contaminantes (Sharpell, Manowitz, 1991; Fassihi, 1991; Brasil, 2001). Embora a pele intacta represente barreira eficiente contra infecções, em peles lesadas o risco de infecção aumenta consideravelmente (Fassihi, 1991). Alguns trabalhos reportam que inóculos contendo $10^{6}$ Unidades Formadoras de Colônias (UFC) são necessários para produção de processos infecciosos em pele íntegra, mas apenas $10^{2}$ UFC são suficientes quando em pele traumatizada ou sob oclusão (Fassihi, 1991; Pinto, Kaneko e Ohara, 2000). Com relação ao tipo de microrganismo contaminante, verifica-se que os microrganismos mais freqüentemente encontrados como contaminantes de produtos são os patogênicos oportunistas, principalmente Pseudomonas spp, as enterobacteriáceas-Enterobacter spp, Serratia spp e Klebsiella spp, além de Escherichia coli e Proteus spp - Flavobacterium spp e Staphylococcus spp (Sharpell, Manowitz, 1991; Fassihi, 1991; Silva, 1999; Pinto, Kaneko, Ohara, 2000).

O processo de fabricação exerce grande influência sobre os níveis de contaminação microbiana do produto, sendo, portanto fundamental entender as diferentes etapas produtivas e se conhecer as fontes e os mecanismos responsáveis pela contaminação. As principais fontes de contaminação a serem consideradas, responsáveis pela carga microbiana total do produto, incluem as fontes diretas - acarretadas por matérias-primas, água e material de acondicionamento utilizados - e as fontes indiretas - decorrentes de procedimentos de limpeza, instalações inadequadas, equipamentos, ambientes produtivos e operadores envolvidos (Sharpell, Manowitz, 1991; Silva, 1999; Macedo, 2000; Pinto, Kaneko, Ohara, 2000).

A finalidade do presente trabalho foi avaliar a qualidade microbiológica de produtos saneantes destinados à limpeza comercializados em São Paulo, fornecendo subsídios para ações de Vigilância Sanitária no que se refere ao atendimento às Boas Práticas de Fabricação e Controle.

\section{MATERIAL E MÉTODOS}

\section{Amostras}

Entre novembro de 2001 a outubro de 2002, foi re- alizado o Programa de Monitoramento de Saneantes Notificados - PROMOSAN, coordenado pela Agência Nacional de Vigilância Sanitária (ANVISA), com o objetivo de avaliar a qualidade desta classe de produtos, disponíveis no comércio nacional.

No Estado de São Paulo, as amostras deste Programa de Monitoramento foram coletadas sob a coordenação do Centro de Vigilância Sanitária do Estado, em estabelecimentos comerciais, abrangendo principalmente produtores estabelecidos no Estado e encaminhadas ao Instituto Adolfo Lutz para a execução das análises programadas. Neste período, foram analisadas 104 amostras, sendo:

Tipo do produto Quantidade de amostras

Amaciante de roupas 26

Detergente para lavar louças 23

Detergente para limpeza geral 22

Detergente automotivo $\quad 04$

Sabão para lavar roupas $\quad 10$

Desengraxantes e Desincrustantes 06

Limpador multi-uso 05

Limpa-alumínio 05

Cera para móveis $\quad 03$

\section{Métodos}

As análises microbiológicas compreenderam:

a) Contagem de bactérias heterotróficas, pela técnica de Semeadura em profundidade (método de "Pour Plate");

b) Contagem de bolores e leveduras, pela técnica de Semeadura em profundidade (método de "Pour Plate");

c) Número Mais Provável de coliformes totais, pela técnica de Tubos múltiplos;

d) Número Mais Provável de coliformes fecais, pela técnica de Tubos múltiplos;

e) Pesquisa e identificação de microrganismos contaminantes.

\section{Preparação da amostra}

Para os ensaios microbiológicos foram utilizadas alíquotas de $10 \mathrm{~g}$ ou $10 \mathrm{~mL}$ do produto a ser analisado, que foram adicionadas a $90 \mathrm{~mL}$ de Caldo Letheen (correspondendo à diluição $10^{-1}$ ). A partir da diluição inicial foram executadas diluições decimais seriadas até a diluição $10^{-4}$, utilizando o mesmo como diluente.

Técnica de semeadura em profundidade

Esta técnica foi utilizada tanto para a determinar a população de bactérias heterotróficas quanto para bolores 
e leveduras, tendo sido executada conforme indicado na Farmacopéia Brasileira (1988), utilizando Ágar caseína de soja e incubação a $35^{\circ} \mathrm{C}$ por 24 a 48 horas, na contagem de bactérias e Ágar Sabouraud dextrose com cloranfenicol $(0,5 \%)$ e incubação a $27^{\circ} \mathrm{C}$, por 5 dias, na contagem de fungos.

\section{Técnica de tubos múltiplos}

Esta técnica foi utilizada para a determinar o número mais provável (NMP) de coliformes presente nas amostras, tendo sido executada conforme indicado na Farmacopéia Brasileira (1988), utilizando Caldo Lauril Sulfato de Sódio e incubação a $35^{\circ} \mathrm{C}$ por 48 horas, na contagem de coliformes fecais e Caldo EC e incubação a $45^{\circ} \mathrm{C}$ por 24 horas, na contagem de coliformes fecais.

\section{Identificação de microrganismos contaminantes}

A identificação dos microrganismos contaminantes foi executada conforme indicado na Farmacopéia Brasileira (1988), utilizando técnicas de coloração de Gram e testes bioquímicos.

\section{RESULTADOS E DISCUSSÃO}

Do total de produtos analisados, $41 \%$ apresentaram crescimento microbiano, sendo que em $96 \%$ das amostras contaminadas foi possível detectar a presença de bactérias heterotróficas; em $21 \%$, a presença de fungos; em $16 \%$, a presença de coliformes e em $5 \%$ a presença de coliformes fecais.

A Figura 1 mostra a porcentagem das amostras que apresentaram microrganismos contaminantes.

Quarenta por cento (40\%) das amostras que apresentaram microrganismos contaminantes eram compostas por amaciantes de roupas, enquanto que $51 \%$ eram compostas de detergentes, sendo que neste último grupo, os detergentes para lavar louças foram os que apresentaram maior proporção de amostras contaminadas.

De modo geral, os produtos que evidenciaram crescimento microbiano apresentaram valores de $\mathrm{pH}$ entre 5,0 e 9,0. Produtos como os limpadores multi-uso, limpa-alumínio e desengraxantes/desincrustantes, que não evidenciaram crescimento microbiano, apresentaram valores de $\mathrm{pH}$ abaixo de 5,0 e acima de 9,0. No caso de produtos em pó, a baixa atividade de água mostrou-se fator impeditivo de eventuais microrganismos contaminantes.

As Figuras 2 e 3 mostram as variações nas populações obtidas para bactérias heterotróficas e fungos e para coliformes, respectivamente.

As amostras estão identificadas por números de 1 a 43 , sendo que aquelas identificadas de 01 a 17 correspondem aos amaciantes de roupas; identificadas de 18 a 20 , correspondem às ceras para móveis; identificada como 21 , ao detergente automotivo; identificadas de 22 a 34, aos detergentes para lavar louças; de 35 a 42, a detergentes para limpeza geral e identificada como 43 , ao detergente para lavar roupas.

Com relação às bactérias heterotróficas e fungos, foram verificadas populações variando de $1,0 \times 10^{1}$ a 1,9 x $10^{6} \mathrm{UFC} / \mathrm{g}$ ou $\mathrm{mL}$, no caso de bactérias e entre $1 \times 10^{1} \mathrm{e}$ $1,5 \times 10^{5} \mathrm{UFC} / \mathrm{g}$ ou $\mathrm{mL}$, no caso de fungos.

Produtos com especificações de qualidade microbiológica estabelecidas, como produtos destinados à higiene pessoal, devem apresentar carga microbiana máxima de $5 \times 10^{3} \mathrm{UFC} / \mathrm{g}$ ou $\mathrm{mL}$, ou até mais rígidas, se considerados os produtos de uso infantil, que devem apresentar carga microbiana máxima de $5 \times 10^{2} \mathrm{UFC} / \mathrm{g}$ ou mL. Apesar dos produtos analisados não se destinarem à higiene

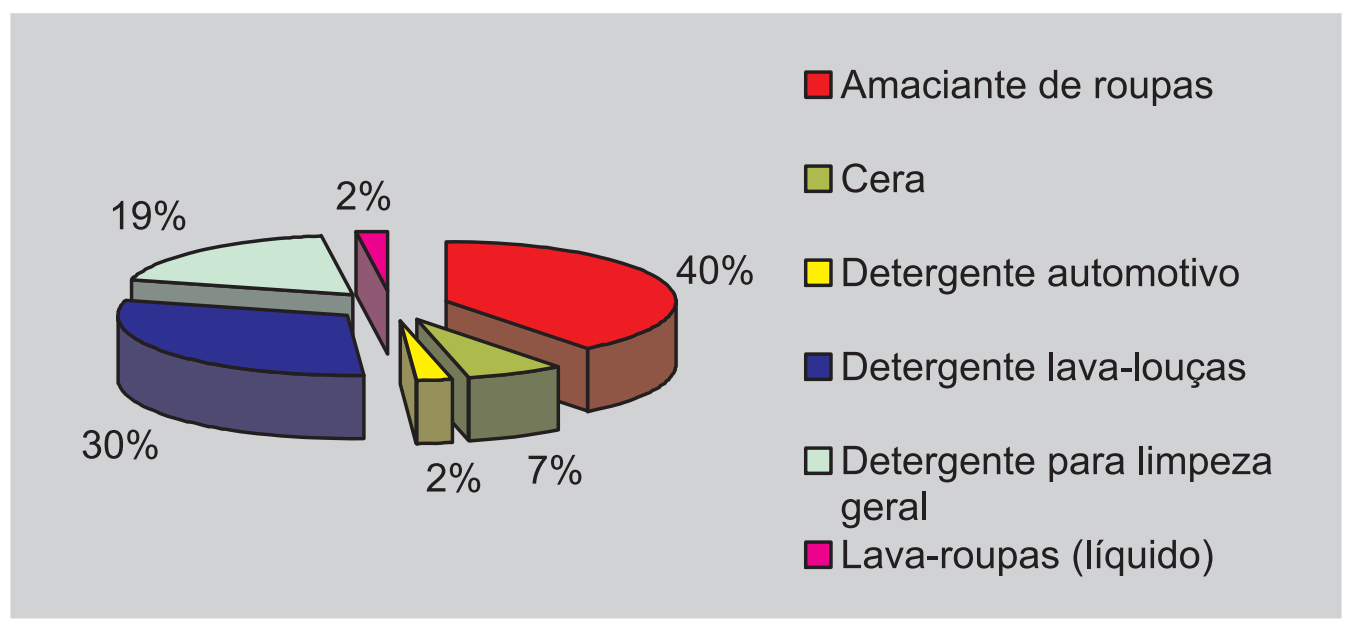

FIGURA 1 - Distribuição das amostras que apresentaram contaminantes microbianos de acordo com o tipo de produto analisado. 


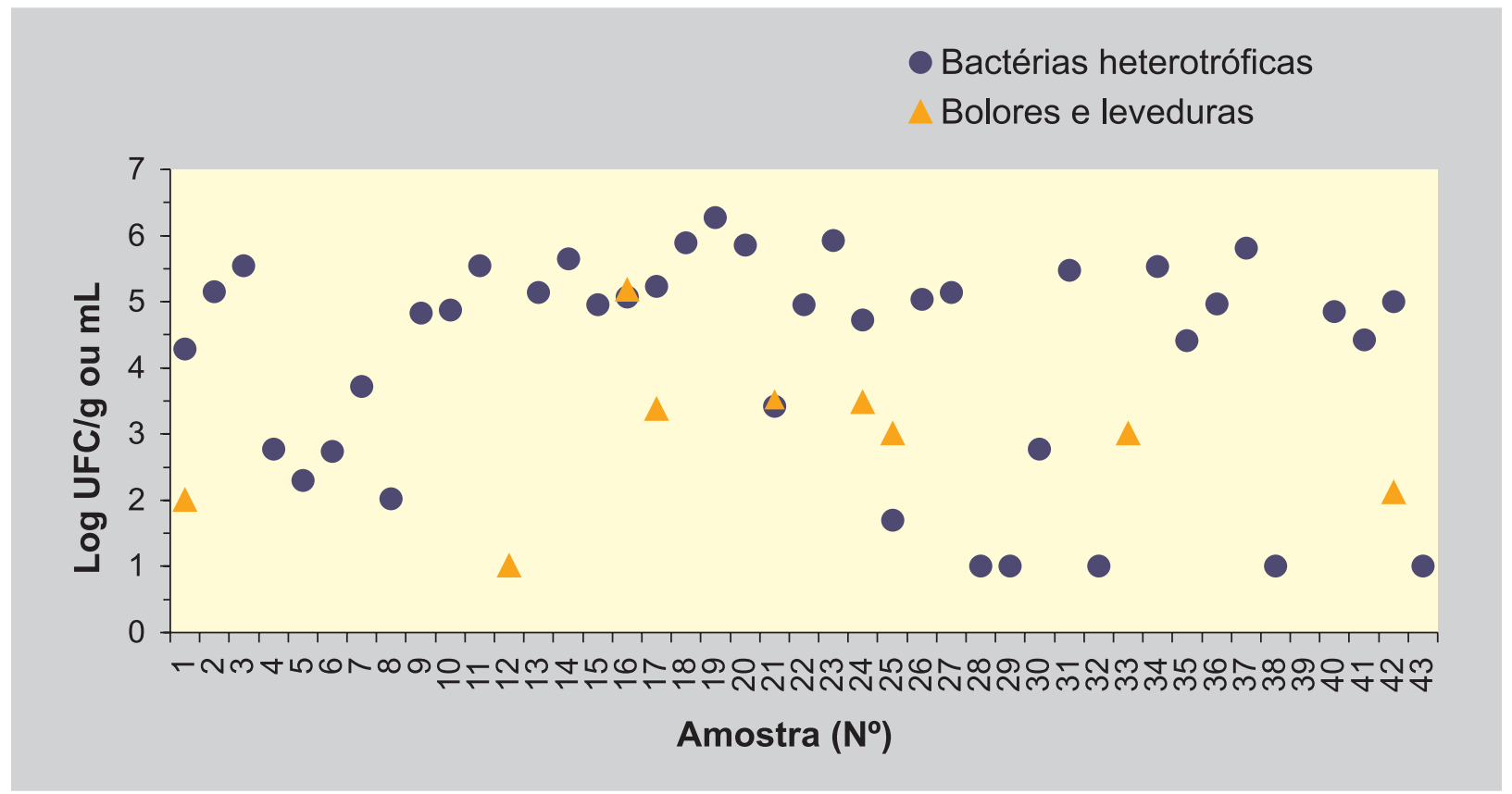

FIGURA 2 - Contagens obtidas para bactérias heterotróficas e fungos nas amostras analisadas.

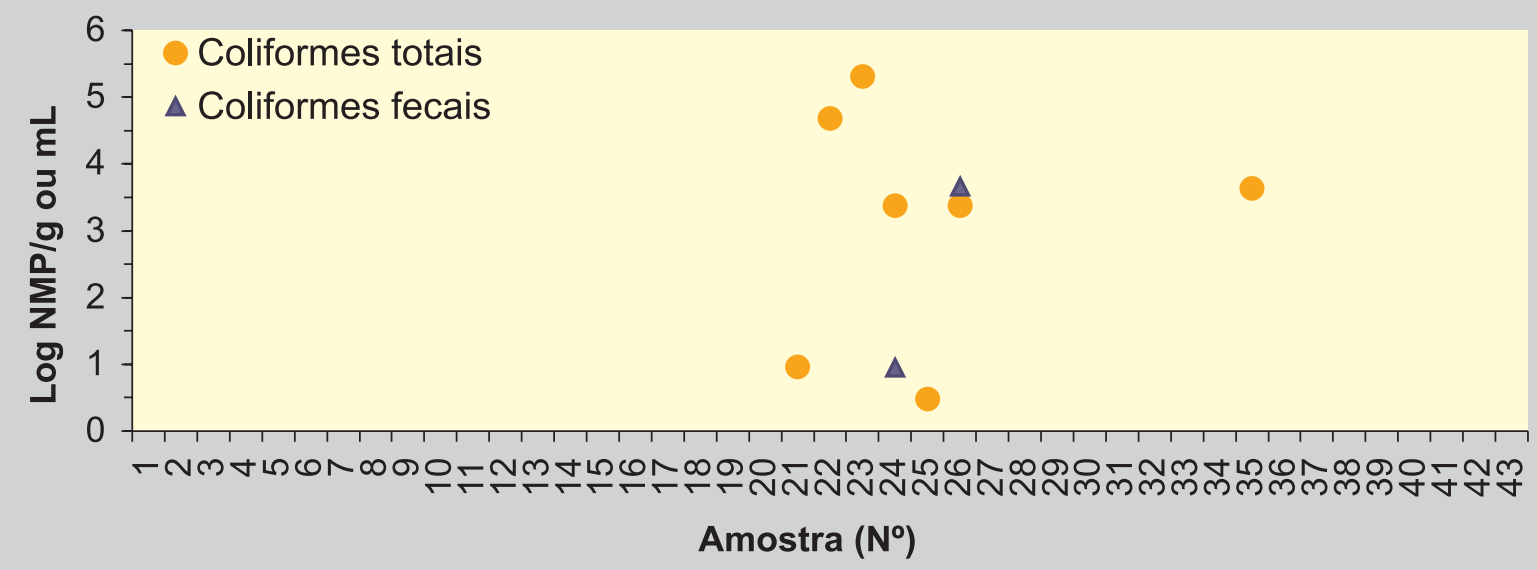

FIGURA 3 - Número mais provável obtido para coliformes de acordo com as amostras analisadas.

pessoal, ao comparar os valores obtidos, verifica-se que a maior parte das amostras analisadas apresentou populações superiores a $5 \times 10^{3} \mathrm{UFC} / \mathrm{g}$ ou $\mathrm{mL}$.

Em relação à presença de coliformes, verificaramse populações estimadas variando de $3 \times 10^{0}$ a $2,1 \times 10^{5}$ $\mathrm{NMP} / \mathrm{g}$ ou $\mathrm{mL}$, tendo sido obtidas apenas para detergentes, principalmente nos destinados a lavar louças.

A Figura 4 considera os tipos de microrganismos observados nas amostras analisadas.

Foi verificada a presença de bactérias Gram (-) não fermentadoras, Enterobacter spp, Klebsiella spp, Pseudomonas spp e Staphylococcus spp coagulase (-). A presença destes tipos de microrganismos, bem como as altas cargas microbianas obtidas nestas amostras podem sugerir a necessidade de procedimentos adequados para o controle de contaminação.

\section{CONCLUSÃO}

Entre os produtos analisados, $41 \%$ apresentaram contaminação microbiana, cuja natureza - seja em termos quantitativos quanto, principalmente, qualitativos - indica um problema de Saúde Pública e a necessidade de controle mais rigoroso no que se refere à implantação das BPF e C 


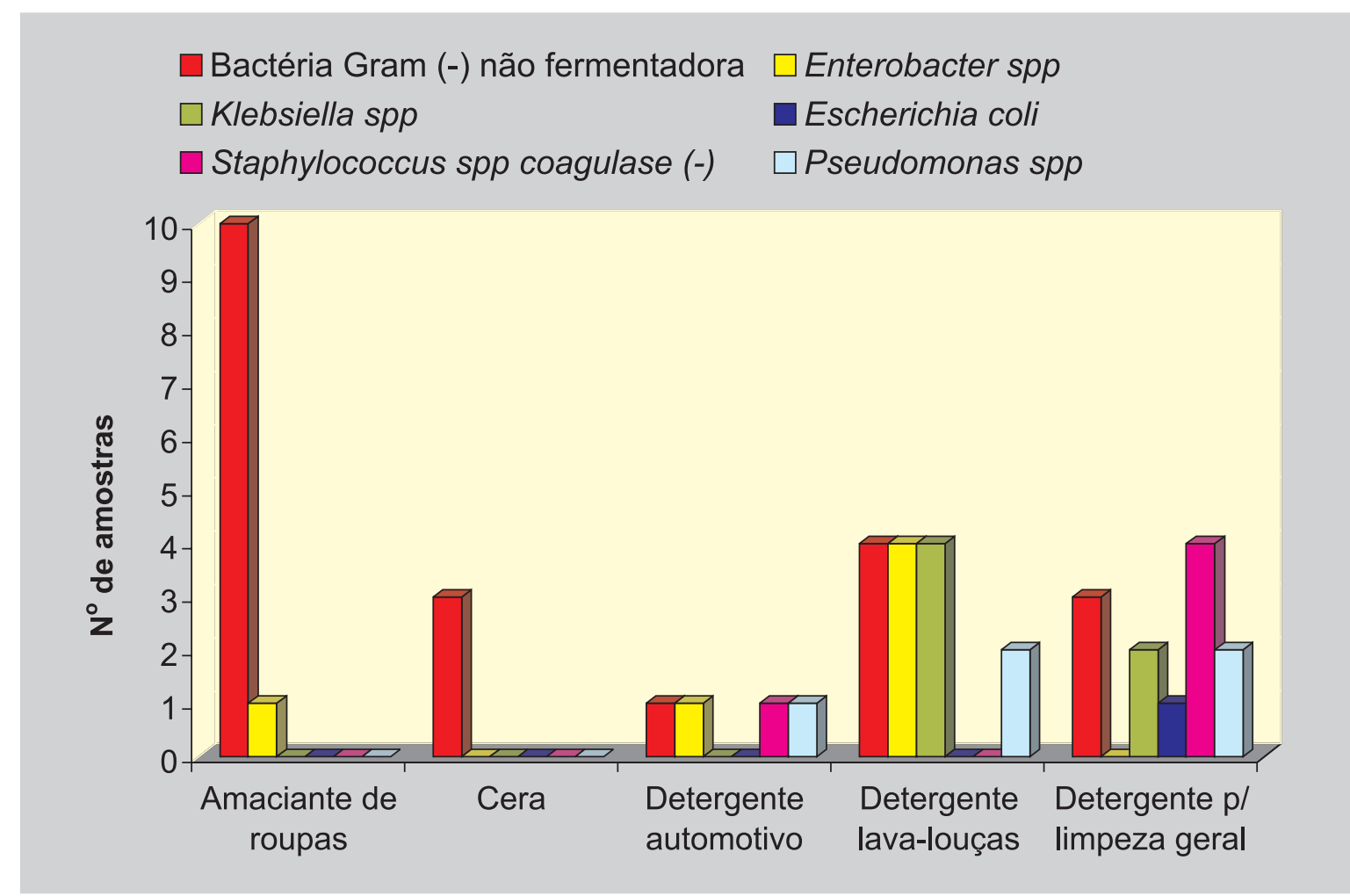

FIGURA IV - Microrganismos isolados em função do tipo de produto analisado.

nas indústrias de saneantes e domissanitários, com a finalidade de garantir a segurança de uso destes produtos.

\section{ABSTRACT \\ Evalution of the microbiological quality of sanitizing products for use in cleaning}

Detergents and similars are products aimed to clean and hygienize inanimate objects and/or ambients. The enterprises dedicated to produce ou import the products mentioned must to accomplish with the Good Manufacturing and Control Pratices, in order to guarantee the quality and be sure about the safety of them. The aim of this study was evaluation of the microbiological quality of detergents and similars products. A hundred and four samples were analised in the period from April, 2001 to October, 2002, and it was verified that $41 \%$ of the products showed evidences of microbial contamination.

UNITERMS: Microrganisms. Contaminants. Detergents

\section{REFERÊNCIAS BIBLIOGRÁFICAS}

BRASIL. Ministério da Saúde. Agência Nacional de Vigilância Sanitária. Saneantes. Registro de Produtos. Como Registrar Saneantes. Legislação. Resolução RDC n.184, de 22 de outubro de 2001. Procedimentos referentes ao registro de produtos saneantes domissanitários e outros de natureza e finalidade idênticas. Disponível em: http://www.anvisa.gov.br/ legis/resol/2001/184_01rdc.htm. Acesso em: 26 nov. 2002.

BRASIL. Ministério da Saúde. Agência Nacional de Vigilância Sanitária. Legislação. Legislação por Tipo de Ato. Resoluções. Resoluções de 1999. Resolução n.481, de 23 de setembro de 1999. Padrões de controle microbiológico para produtos de higiene pessoal, cosméticos e perfumes. Disponível em: http:// www.anvisa.gov.br/legis/resol/481_99.htm. Acesso em: 26 nov. 2002. 
BRASIL. Ministério da Saúde. Agência Nacional de Vigilância Sanitária. Legislação. Legislação por Tipo de Ato. Portarias. Portarias - Anteriores a 1997. Portaria n.327, de 30 de julho de 1997. Diretrizes estabelecidas pelos Regulamentos Técnicos - Boas Práticas de Fabricação e Controle (BPF e C). Disponível em: http:// www.anvisa.gov.br/legis.portarias/327 97.htm. Acesso em: 26 nov. 2002.

BRITISH Pharmacopoeia 1993. London: Her Majesty's Stationary Office, 1993. p.A519.

EUROPEAN Pharmacopoeia. 3.ed. Strasbourg: Council of Europe, 1997. p.287-288.

FARMACOPÉIA BRASILEIRA. 4.ed. São Paulo: Atheneu, 1988. pt.2, v.5.1.6-v.5.1.7-6

FASSIHI, R.A. Preservation of medicines against microbial contamination. In: BLOCK, S., ed. Disinfection, sterilization and preservation. Philadelphia: Lea \& Febiger, 1991. cap.50, p.871-886.
MACEDO, J.A.B. Águas \& águas. Juiz de Fora: Ortofarma, 2000. 505p.

PINTO, T.J.A.; KANEKO, T.M.; OHARA, M.T. Controle biológico de qualidade de produtos farmacêuticos, correlatos e cosméticos. São Paulo: Atheneu, 2000. $309 \mathrm{p}$.

SHARPELL, F.; MANOWITZ, M. Preservation of cosmetics. In: BLOCK, S., ed. Disinfection, sterilization and preservation. Philadelphia: Lea \& Febiger, 1991. cap.51, 887-900.

SILVA, C.H.P.M. Bacteriologia: um texto ilustrado. Teresópolis: Eventos, 1999. 531p.

Recebido para publicação em 15 de janeiro de 2003. 